\title{
Understanding the impact of 'cost' under MACRA: a neurointerventional imperative!
}

\author{
Gabriela Spilberg, ${ }^{1}$ Gregory N Nicola, ${ }^{2}$ Andrew B Rosenkrantz, ${ }^{3}$ Ezequiel Silva III, ${ }^{4}$ \\ Clemens M Schirmer, ${ }^{5}$ Brian B Ghoshhajra, ${ }^{1}$ Nirmal Choradia, ${ }^{6}$ Rose Do, ${ }^{7}$ \\ Joshua A Hirsch ${ }^{8}$
}

\begin{abstract}
- Additional material is
published online only. To view please visit the journal online (http://dx.doi.org/10.1136/ neurintsurg-2018-013972).
\end{abstract}

'Department of Radiology, Massachusetts General Hospital, Boston, Massachusetts, USA ${ }^{2}$ Hackensack Radiology Group, Hackensack, New Jersey, USA ${ }^{3}$ Department of Radiology, NYU Langone Medical Center, New York, USA

${ }^{4}$ South Texas Radiology Group, San Antonio, Texas, USA

${ }^{5}$ Department of Neurosurgery, Neuroscience Institute, Geisinger, Wilkes-Barre,

Pennsylvania, USA

${ }^{6}$ Acumen, LLC, Burlingame,

California, USA

${ }^{7}$ Department of Cardiology and Cardiac Surgery, Veterans Affairs Medical Center, Long Beach,

Kaiser Permanente of Southern California, Acumen, LLC, Long Beach, California, USA

${ }^{8}$ Interventional Neuroradiology, Massachusetts General Hospital, Harvard Medical School, Boston, Massachusetts, USA

\section{Correspondence to} Dr Joshua A Hirsch,

Interventional Neuroradiology, Massachusetts General Hospital, Harvard Medical School, Boston, MA 02114, USA; hirsch@ snisonline.org

Received 28 March 2018 Revised 23 April 2018 Accepted 26 April 2018 Published Online First 23 July 2018

Check for updates

\section{To cite: Spilberg G,}

Nicola GN, Rosenkrantz AB

et al. J Neurolntervent Surg 2018:10:1005-1011.

\section{ABSTRACT}

The cost of providing healthcare in the United States continues to rise. The Affordable Care Act created systems to test value-based alternative payments models. Traditionally, procedure-based specialists such as neurointerventionalists have largely functioned in, and are thus familiar with, the traditional Fee for Service system. Administrative charge data would suggest that neurointerventional surgery is an expensive specialty. The Medicare Access and CHIP Reauthorization Act consolidated pre-existing federal performance programs in the Merit-based Incentive Payments System (MIPS), including a performance category called 'cost'. Understanding cost as a dimension that contributes to the value of care delivered is critical for succeeding in MIPS and offers a meaningful route for favorably bending the cost curve.

\section{INTRODUCTION}

The United States has the most expensive healthcare system in the world with 2016 health expenses estimated at $\$ 9892.3$ per person, representing approximately $17.2 \%$ of the Gross Domestic Product. ${ }^{1}$ The Affordable Care Act of 2010 (ACA) made significant efforts toward reducing the growth of healthcare costs. ${ }^{2} 3$ In terms of those controls, the ACA created two independent boards that theoretically could exercise substantial control over American healthcare: the now defunct Independent Payment Advisory Board (IPAB, whose primary role was to achieve savings theoretically without compromising coverage or quality) and the Patient-Centered Outcomes Research Institute (PCORI, whose primary function is to explore the effectiveness of diverse medical treatments). ${ }^{4-6}$ The ACA also created the Center for Medicare and Medicaid Innovation (CMMI) to help implement models of value-driven care and design new alternative payment models. ${ }^{7}$ One of the central concepts of the CMMI is to support the transition from a volume-based payment model into an outcome-focused and resource-efficient healthcare system. ${ }^{8}$

The Medicare Access and CHIP Reauthorization Act (MACRA) of 2015 ended the Sustainable Grown Rate formula, which was a controversial method used by the Centers for Medicare \& Medicaid Services (CMS) to regulate spending by Medicare on physician services. ${ }^{9-12}$ Additionally, the MACRA expanded the Obama administration's view of healthcare reform by focusing on three main principles: ${ }^{13} 14$

1. The use of incentives to stimulate high-value care by tying both hospital and physician payments to new value-based payment models.

2. Increase integration of care delivery, with more efficient teams and care coordination, as well as more awareness by providers to population health.

3. Use of health information technology to optimize patient care.

Implicit to MACRA is the emphasis on transitioning healthcare delivery from a traditional Fee for Service (FFS) volume-based payment model into an approach that incentivizes value-based patient-centric care. This act provided two pathways forward for future provider payments. The Merit-Based Incentive Payment System (MIPS) is the non-linear descendent of FFS with a superimposed value purchasing methodology. ${ }^{15}{ }^{16}$ In April 2016, CMS introduced incremental information regarding MACRA implementation, the Quality Payment Program (QPP), under which physician compensation (Medicare part B payment) was tied to either one of these tracks: MIPS or Advanced Alternative Payment Models (APMs). ${ }^{11} \quad 17 \quad 18$ Recently, CMS has further delineated the specific goals of the QPP, stating that the idea is to "create a simpler, sustainable Medicare program. ${ }^{19}$

To achieve the status of Qualified APM Participant (QP) through participation in an Advanced APM requires fulfilling predetermined strict criteria. ${ }^{2021}$ Eligible professionals and groups were informed during 2017 regarding their APM or MIPS inclusion status. QP status releases providers of much of its administrative reporting burden, yields generous financial incentives, and ultimately a separate, higher, conversion factor. ${ }^{22} 23$ Multiple additional models have been previously discussed in this journal including bundled payments, Accountable Care Organizations (ACOs), and Physician-Focused Payment Models (PFPM). ${ }^{22}$ 24-26

Under the current MACRA framework, the majority of eligible physicians including neurointerventionalists will use the MIPS pathway. ${ }^{27} 28$ Under this route, physicians can engage either as individuals, groups, or as a virtual group, as long as more than one taxpayer identification number (TIN) is attributable to a virtual group. ${ }^{29}$ Recently, it has been suggested that participating as a group or virtual group may be beneficial for specialists 
Table 1 Comparison of the two metrics currently in use for MIPS performance year 2018, and episode-based cost, currently under development by CMS/Acumen LLC 31374041

\begin{tabular}{|c|c|c|c|}
\hline & $\begin{array}{l}\text { Medicare spending per beneficiary } \\
\text { (MSPB) clinician measure }\end{array}$ & $\begin{array}{l}\text { Total per capita costs for all attributed } \\
\text { beneficiaries (TPCC) }\end{array}$ & Episode-based cost measure \\
\hline CMS definition & $\begin{array}{l}\text { 'assesses the cost to Medicare of services } \\
\text { performed by an individual clinician during } \\
\text { an MSPB episode.' } \\
\text { 'compares observed and expected episode } \\
\text { costs.' }\end{array}$ & $\begin{array}{l}\text { 'evaluates the overall cost of care provided } \\
\text { to beneficiaries attributed to clinicians.' }\end{array}$ & $\begin{array}{l}\text { 'the cost to Medicare for the items and } \\
\text { services furnished to patients during } \\
\text { an episode of care... Episode-based } \\
\text { cost measures are developed to inform } \\
\text { clinicians on the cost of care for an episode } \\
\text { during which they manage the care for } \\
\text { an acute medical condition or perform a } \\
\text { procedure.' }\end{array}$ \\
\hline Numerator & $\begin{array}{l}\text { 'Sum of the ratio of payment-standardized } \\
\text { observed to expected MSPB episode costs } \\
\text { for all MSPB episodes for the TIN-NPI or } \\
\text { TIN.' }\end{array}$ & $\begin{array}{l}\text { 'sum of the annualized, risk-adjusted, } \\
\text { specialty-adjusted Medicare Part A and Part } \\
\text { B costs across all beneficiaries attributed to } \\
\text { a TIN-NPI, within a TIN or TIN-NPI.' }\end{array}$ & Under development. \\
\hline Denominator & $\begin{array}{l}\text { 'total number of MSPB episodes for the } \\
\text { TIN-NPI or TIN.' }\end{array}$ & $\begin{array}{l}\text { 'number of all Medicare beneficiaries who } \\
\text { received Medicare-covered services and are } \\
\text { attributed to a TIN-NPI, within a TIN or TIN- } \\
\text { NPI, during the performance period.' }\end{array}$ & Under development. \\
\hline Standardized & Yes & Yes & Yes \\
\hline Risk-adjusted & Yes & Yes & Yes \\
\hline Specialty-adjusted & Yes & Yes & Variable \\
\hline Reporting period & $\begin{array}{l}3 \text { days prior to the index admission to } 30 \\
\text { days after hospital discharge }\end{array}$ & 1 year (anualization of costs) & Variable \\
\hline Attribution & $\begin{array}{l}\text { Pluarity of Part B services during index } \\
\text { admission }\end{array}$ & $\begin{array}{l}\text { PCP first (only beneficiaries who received } \\
\text { a primary care service during the } \\
\text { performance period are considered in } \\
\text { attribution) }\end{array}$ & $\begin{array}{l}\text { Expected to be variable depending on } \\
\text { 'procedural', 'acute inpatient medical } \\
\text { condition' and 'chronic condition' }\end{array}$ \\
\hline Exclusions & $\begin{array}{l}\checkmark \text { Patient death during window } \\
\checkmark \text { Beneficiaries not enrolled in Medicare } \\
\text { part A and B during } 93 \text { days prior index } \\
\text { through } 30 \text { days post discharge } \\
\checkmark \text { The index admission for the episode } \\
\text { did not occur in a hospital paid under the } \\
\text { Inpatient Prospective Payment System } \\
\text { (IPPS) } \\
\checkmark \text { Discharge of the index admission } \\
\text { occurred in the last } 30 \text { days of the } \\
\text { performance period } \\
\checkmark \text { The index admission for the episode } \\
\text { is involved in an acute-to-acute hospital } \\
\text { transfer } \\
\checkmark \text { The index admission occurs within the } \\
30 \text {-day post-discharge period of another } \\
\text { MSPB episode } \\
\sqrt{T} \text { The index admission inpatient claim } \\
\text { indicates a } \$ 0 \text { actual payment or a } \$ 0 \\
\text { standardized payment }\end{array}$ & $\begin{array}{l}\checkmark \text { Beneficiaries not enrolled in Medicare } \\
\text { part } A \text { and } B \text { during the performance period } \\
\checkmark \text { Beneficiaries enrolled in a private } \\
\text { Medicare health plan for any month during } \\
\text { the performance period } \\
\checkmark \text { Beneficiaries resided outside the US } \\
\text { during any month of the performance } \\
\text { period }\end{array}$ & $\checkmark$ Depends on the episode group \\
\hline Level of reporting & TIN-NPI or TIN & TIN-NPI, both within a TIN or TIN-NPI & TIN-NPI \\
\hline Legacy (bulk) measures & $\begin{array}{l}\text { Medicare spending per beneficiary (MSPB) } \\
\text { Measures the Medicare Part A and Part B co } \\
\text { Total per-capita cost for all attributed benefi } \\
\text { Measures all Medicare Part A and Part B cos }\end{array}$ & $\begin{array}{l}\text { sts of care related to inpatient hospital visits } \\
\text { iciaries } \\
\text { sts }\end{array}$ & \\
\hline Episode measures & $\begin{array}{l}\text { 1. Aortic/mitral valve surgery } \\
\text { 2. Cholecystectomy and common duct explo } \\
\text { 3. Colonoscopy } \\
\text { 4. Coronary artery bypass graft (CABG) } \\
\text { 5. Hip replacement and repair } \\
\text { 6. Inpatient hip/femur fracture or dislocation } \\
\text { 7. Knee arthroplasty (replacement) } \\
\text { 8. Lens and cataract procedures } \\
\text { 9. Mastectomy for breast cancer } \\
\text { 10. Transurethral resection of the prostate }\end{array}$ & ration & \\
\hline Episode-based cost measures & \multicolumn{3}{|c|}{$\begin{array}{l}\text { See long list at https://www.cms.gov/Medicare/Quality-Initiatives-Patient-Assessment-Instruments/Value-Based-Programs/MACRA- } \\
\text { MIPS-and-APMs/draft-list-of-care-episode-and-patient-condition-groups-and-codes.zip }\end{array}$} \\
\hline
\end{tabular}


MIPS Medicare Spending Per Beneficiary clinician measure

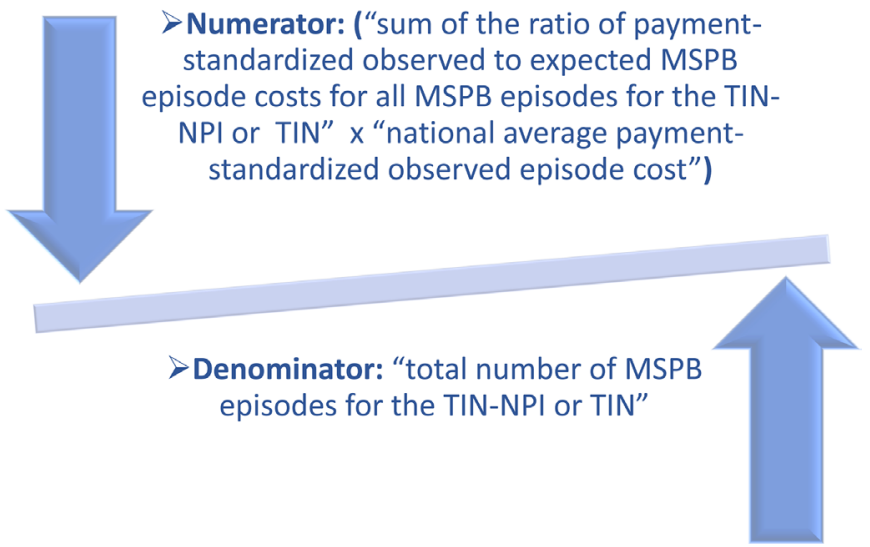

Figure 1 Originally developed for the value modifierr program, the MSPB clinician measure was updated in 2017 for the MIPS cost performance category. ${ }^{41}$

such as neurointerventionalists. The rationale includes greater flexibility in reporting mechanisms, operational simplification, and overall cost reduction. However, this will vary by specific practice circumstance. ${ }^{30}$

Four performance categories will be independently evaluated and scored under MIPS, collectively yielding an overall Final Score (FS). A FS between 0 denoting non-participation and 100 results in a positive, neutral, or negative adjustment of the traditional FFS payment. The categories are quality, improvement activities, advancing care information, and cost. ${ }^{18}$ The first three categories were an expansion of existing programs - Physician Quality Reporting System (PQRS), the Physician Value-based Payment Modifier (VM), and the Medicare Electronic Health Record (EHR) Incentive Program for Eligible Professionals (EPs), but cost, while seemingly a new metric is, in fact, a carryover from the VM under the ACA. Improvement activity is a new true category under MIPS. Medicare part payments will be adjusted up to + or - $4 \%$ depending on participants' FS. Subsequently, compensation variation is expected to shift further, to a maximum of + or $-9 \%$ by 2022 , creating an overall payment disparity absent scaling factors that potentially approaches $20 \% .^{22} 3132$

The MIPS cost performance category is being calculated starting in performance year (calendar year - CY) 2017. However, it is weighted at $0 \%$ in the FS. Even though cost does not require specific reporting at present, the other MIPS data of 2017 CY must be reported by the end of March 2018. ${ }^{33}$ For CY 2018 (2020 payment year), cost will be weighted at 10\% of the FS. ${ }^{34} 35$ Until the recently dropped congressional budget, for the following CY 2019, FS was expected to increase to 30\% wt costbased. With the Bipartisan Budget Act (BBA) of 2018, CMS has been given greater flexibility in pursuing years for reweighting of cost to $10 \%$ through $2021 .^{36}$ The authors believe it likely that these changes will slow the momentum considerably and that cost will not be weighted to $30 \%$ in 2019 .

The recently published 2018 MACRA final rule ${ }^{35}$ provides the following overall FS weights: Performance year 2017: Quality 60\%, Cost 0\%, Improvement Activities 15\%, and Advancing Care Information 25\%. Performance year 2018: Quality 50\%, Cost 10\%, Improvement Activities 15\%, and Advancing Care Information $25 \%$.

\section{WHAT IS MIPS 'COST'?}

The concept of cost under MIPS is to empower clinicians with comparison information on healthcare resource spending with the goal of helping decrease unneeded costs and cost growth. Often, it is believed that clinicians do not make decisions aware of expenses or even consider different values for various choices. ${ }^{37}$ Clinicians were first held accountable for cost under the Patient Protection and Affordable Care Act of 2010 through of the federal value modifier program (VM). The VM brought responsibility for cost via three performance metrics: Medicare spending per beneficiary (MSPB); total per capita costs (TPCC) for all attributed beneficiaries; and PCC of beneficiaries with four specific conditions. 3839

Cost measurement in MIPS differs from the VM in several substantive ways table 1 . First, the four TPCC measures with specific conditions that were part of the VM are not used in MIPS. New episodic measures with significant clinical input from start to finish are now under construction which CMS intends to propose to adopt in future rulemaking. ${ }^{35}$ Second, there are some differences between the VM and MIPS versions of the MSPB and TPCC measures. ${ }^{40}{ }^{41}$ For instance, the threshold number of attributed episodes needed per clinician before MSPB was deemed valid measurement of that said physician's cost and was reduced from 125 episodes (the value in the final year of the VM) to 35 for MIPS MSPB, seemingly expanding the number of clinicians to which this measurement tool would apply. Lastly, altering the attribution methodology of MSPB, which previously prescribed attribution of patients to the TIN with plurality of applicable part B Medicare claims during a performance period under the VM, but now would attribute patients to each unique NPI/TIN combination with plurality of applicable part B Medicare claims during the performance period. It is worth noting that the VM specialty adjustment was removed. If a clinician chose to report MIPS MSPB as an individual, then only episodes attributed to them for MSPB during the performance period would count toward the MSPB threshold. However, if the clinician reported MIPS MSPB with a group, then all clinicians in the reporting TIN's attributes will be summed together, counting toward the threshold value of 35 episodes. This last modification introduced a strategic decision point for clinicians in MIPS which did not exist in the VM. Clinicians that may not have reached minimum threshold values for MSPB if they reported as individuals, may be able to, if they decide to report as part of a group. ${ }^{3738}$ In the case of TPCC, the finalized version for use in MIPS differs slightly from the measure included in the VM. First, while the VM version of the measure attributes at the TIN level, the MIPS version of the measure attributes at the Taxpayer Identification Number/National Provider Identifier (TIN/NPI) level, with the option to report at either the TIN-NPI or TIN level. Second, for attribution in the MIPS version, the definition of primary care services was expanded to include care coordination codes for chronic care management (CCM) and transitional care management (TCM). Finally, attribution in the MIPS version of the TPCC measure excludes nursing visits that occur in a Skilled Nursing Facility (SNF). ${ }^{29}$

\section{MSPB: a deeper dive}

MSPB is the cost of dollars per patient on Medicare Part A and Part B for a professional or group during an episode. Medicare part D covered drugs that are not included in this calculation. The MSPB episode is temporally defined in a 'window', starting 3 days before hospital admission (index admission) and ending 30 days after hospital discharge. This metric was conceptualized as CMS's tool for assessing hospitals and physician's financial 
MIPS Total Per Capita Costs for All Attributed Beneficiaries measure

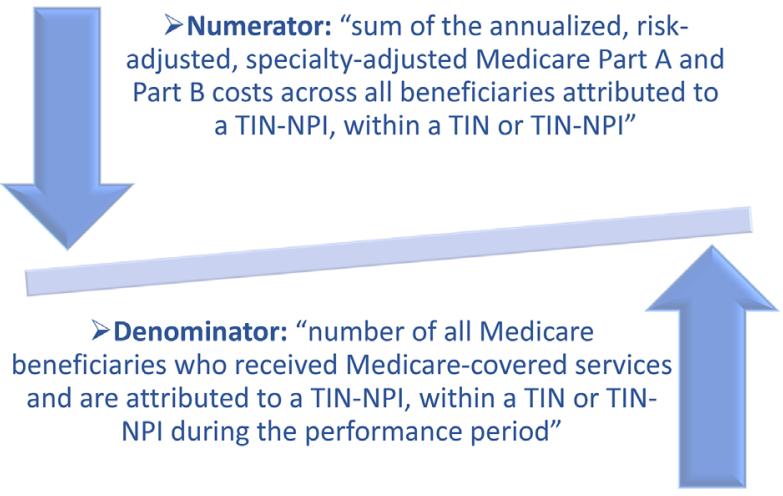

Figure 2 Originally developed for the value modifier program, the TPCC or all attributed beneficiaries measure was updated in 2017 for the MIPS cost performance category. ${ }^{40}$

efficiency in the VM program ${ }^{32}$ and updated into MIPS. ${ }^{41}$ This metric aims to incentivize care coordination, reduce fragmentation, and improve efficiency. ${ }^{29}$ MSPB does not delineate legitimate and justifiable differences in cost in making its calculation, and therefore it is a blunt instrument. This situation is problematic for NI specialists who in the absence of an episode, could default into MSPB as a measure. The updated MSPB is calculated based on seven steps with the specified formula (figure 1):

1. Define the population of index admissions.

2. Calculate payment-standardized episode costs.

3. Calculate expected episode costs.

4. Exclude outliers.

5. Attribute episodes to a TIN-NPI.

6. Calculate the MSPB measure for the TIN-NPI or TIN.

7. Report the MSPB measure for the TIN-NPI or TIN.

MSPB attribution has changed in two fundamental ways.

1. Under VM, MSPB was first attributed to a TIN with the plurality of part B services on the index patient (it was subsequently assigned to an NPI, but this was an insignificant bookkeeping attribute). Under MIPS, the attribution occurs at the NPI-TIN or TIN level depending on whether you report as an individual, group, or virtual group. This change in methodology has strategic implications as it is harder to get an attribute as an NPI-TIN than it is as a TIN. This strategy did not exist under VM.

2. The threshold of attributes changed several times during VM but ended up at 125. In MIPS the threshold is 35 .

\section{TPCC: a deeper dive}

The TPCC for all attributed beneficiaries considers all Medicare Part A and B spending for each beneficiary, excluding Medicare Part D covered drugs. The measurement is customized by specialty, annualized, standardized, and also risk-adjusted. ${ }^{42} 43$ This metric was also developed in the VM program and modified for MIPS. ${ }^{40}$ This variable aims to identify and promote providers who yield high-quality care in an efficient fashion. TPCC will most likely apply to primary caregivers. The updated TPCC calculation is also based on seven steps, with the specified formula (figure 2):

1. Attribute beneficiaries to TIN-NPI.

2. Calculate payment standardized per-capita costs.

3. Annualize costs.

4. Risk-adjusted costs.

5. Specialty-adjusted costs.
6. Calculate the TPCC measure for the TIN-NPI or TIN.

7. Report the TPCC measure for the TIN-NPI or TIN.

Both MSPB and TPCC are risk-adjusted metrics, which take into consideration beneficiaries' age and comorbidities. The risk-adjustment methodology for both is based on the CMS Hierarchical Condition Category (CMS-HCC) model, which is used for the Medicare Advantage program. ${ }^{44}$ However, there are distinct updates developed for each of the two metrics, beyond the scope of this paper.

The clinical episode-based measure is a novel, third metric, currently under development. These measures are the most likely to impact neurointerventionalists. The authors of this manuscript would argue that being able to participate is indeed beneficial. It will not be used for CY 2017 or 2018, with the expectation that it will ultimately be used for the cost score. Clinical episode-based measures are a Medicare Part A and B claim-based platform, which ties services and items delivered to address a given medical condition during a timeframe. ${ }^{31}$ The episode-based cost represents the price to Medicare for particular services and needs of a patient during a specific episode of care. ${ }^{37}$ In general, there are two distinct ways to trigger an episode, either based on professional CPT/ICD-10-based claims or inpatient DRG claims submitted. Five elements are fundamental in the episode-based cost: ${ }^{25}$

1. Defining an episode group.

2. Assignment of the cost to the episode group.

3. Connecting an episode group to specific clinicians.

4. Risk adjustment of the episode groups.

5. 'Coupling' cost and quality (which incorporates outcomes, processes of care, and patient engagement/experience).

\section{CY 2017 (ALSO REFERRED AS THE TRANSITIONAL YEAR)}

The concept of the transitional CY 2017 is essential to note, despite it having already passed. It demonstrates the desire by CMS to allow clinicians an opportunity to experience how the program will work, and to iterate into the reporting processes of the other metrics as well as the development of specifics for each category. ${ }^{29}$ Cost was not used to calculate the FS in the transitional year. ${ }^{35}$

\section{CY 2018}

For $2018 \mathrm{CY}, 10 \%$ of the FS will be calculated based on the average of TPCC for all attributed beneficiaries and MSPB. The final rule of the Quality Payment Program ${ }^{35}$ opted for a $10 \%$ weight and is an attempt to soften the transition for the subsequent year when cost will be scored at $30 \%$ as has now been actively addressed in the BBA of $2018 .{ }^{36}$ CMS will grade eligible physicians and groups using administrative claims data if they meet the case minimum for the metric and if a benchmark is available for comparison. If only one criterion can be evaluated, this single number will represent the whole cost score. The10 episode-based cost measures that were assessed during 2017 CY will not be used for the 2018 CY and thus will not be covered here.

\section{TRANSITIONING FROM CY 2017 TO 2018: IMPROVEMENT FS FOR COST}

Starting CY 2018, performance scores will be available to the cost metric. ${ }^{34}$ If there is data available, CMS will assign a grade for statistically significant changes. If no information is available, a score of 0 will be assigned, nevertheless this has been abolished in years 3,4 , and 5 in the BBA of $2018 .^{35}$ 
Box 1 Episode-based groups, under development

1. Elective outpatient percutaneous coronary intervention (PCI).

2. Knee arthroplasty.

3. Revascularization for lower extremity chronic critical limb ischemia.

4. Routine cataract removal with intraocular lens (IOL) implantation.

5. Screening/surveillance colonoscopy.

6. Intracranial hemorrhage or cerebral infarction.

7. Simple pneumonia with hospitalization.

8. ST-elevation myocardial infarction (STEMI) with PCI.

For CY 2018, CMS has contracted with Acumen LLC to develop a new episode of care system, currently under testing, to comply with the MACRA rules. ${ }^{35}$ Acumen LLC is a research and consulting firm which specializes in health policy and traditionally works with government agencies ${ }^{45} 46$ that CMS contracted to this endeavor. This entity engaged two separate subgroups to help with the process: a conglomerate of seven Clinical Subcommittees (CS) and Technical Expert Panels (TEPs). ${ }^{37}$ Of note, at least four NI specialists are involved in the Acumen effort.

The primary role of these subgroups is to engage in the process development of this new system. Important goals include determining how to trigger episodes (to define patient cohorts), establishing episodic windows of care, assigning services to episodes, and tailoring risk adjustment to the episode group. The TEPs have a more general composition, including members with varied backgrounds such as researchers, statisticians, subject matter experts, patients, and caregivers. The TEP's central focus is to evaluate resource utilization, category development, and quality metric alignment. Clinical Subcommittees are less broad, being subspecialty-oriented with a defined clinical background. The objective of each panel or subcommittee is to assist in developing specifications of the episode groups (such as what are the triggering episodes, diagnosis codes for triggering episode groups, timelines, what services should and should not be included, etc). ${ }^{37}$

With support from these two types of expert panels and input/ comments from the public/stakeholders, a list of eight episodebased groups (box 1) has been created based on the following criteria: (A) potential impact on Medicare spending. (B) clinical coherence regarding a patient population that has a similar stage and severity of a particular illness or condition. (C) the measure's opportunity for improvement. (D) the measure's opportunity for alignment with established quality indicators. Relevant factors that were accounted for included 'volume of beneficiaries impacted by the condition or procedure, the share of cost to Medicare impacted by the condition or procedure, the number of clinicians/clinician groups attributed, and the potential for alignment with existing quality measures. ${ }^{31}$

\section{The process of episode group development \\ Defining the episode group}

Episode groups are units to represent an assemblage of medical services to treat a medical condition. By creating this metric, it is possible to calculate the total cost involved in the care of a defined patient population. The concept is that this unit should be integral, including all relevant services and needs to a specific episode, including diagnostic and treatment procedures, ancillary items, as well as needs following the initial treatment period, extending into follow-up care or treatment of complications that may occur from those services. An episode is a unit of an episodic group for a determined patient and clinician, within a timeline. Moreover, sub-groups can be formed to define more homogeneous patient cohorts. The CS will define clinical roles relevant to an episode based on the service being a trigger event for an episode group, or the service being considered as an assigned rule. $^{37}$

\section{Attributing the episode group to the responsible clinician(s)}

When episodes are initiated, clinicians will be assigned through the TIN-NPI documented in the NPI field on the Physician/Supplier Part B. It is desirable that clinicians are aware at the time of services if they will be associated with the specific episode of care. For procedural episodes, the episode is linked to the physician executing the trigger service (CPT/ HCPCS procedure codes). For acute inpatient medical condition episodes, the assignment is related to the professional responsible for billing the minimum of $30 \%$ of the inpatient evaluation and management (E\&M) services during an inpatient admission with the medical Medicare Severity Diagnosis-Related Groups (MS-DRGs). ${ }^{37}$ The concept is to ensure that episodes are assigned to professionals who can meaningfully impact episode spending. Patient Relationship Codes (PRCs) are designed to more precisely detail the level of clinical engagement in the episode. ${ }^{47}$ The codes are currently in a voluntary reporting period and whether and how the codes are reported will not affect Medicare payment. During the voluntary period, CMS will be collecting data for validity and reliability testing of the codes before their potential use in the attribution methodology for cost measures. More than one physician can be responsible for the episode of the same patient, varying with their role. ${ }^{31}$ While the general concept is intuitive the precise threshold of assessing which clinician has significant influence over the medical expenditures is less clear and may be subject to further refinement based on feedback from real-world testing. It remains uncertain whether measures will be optimally assessed by enumerating encounters or evaluation and management claims.

\section{Assigning costs to the episode group}

Three types of episode groups have distinct cost metrics: procedural (specific aim such as surgery; ex; cholecystectomy or hip arthroplasty); acute inpatient medical condition (self-limited acute illness or treatment of flares/exacerbation of a condition requiring hospitalization; ex: acute myocardial infarction, gastrointestinal bleed); and chronic condition (takes into consideration patient's previous medical history and current state of health; ex: diabetes). Initially, Acumen will work in the development of procedural and acute inpatient episode-based cost measures. Chronic conditions will only be addressed at a later stage. Five out of the eight episode groups tested are procedural episode groups, predominantly managed in outpatient and elective settings: elective outpatient PCI, knee arthroplasty, revascularization for lower extremity chronic critical limb ischemia, routine cataract removal with IOL implantation, and screening/surveillance colonoscopy. The additional three episode groups are acute inpatient groups and include intracranial hemorrhage/cerebral infarction, pneumonia with hospitalization, and STEMI with PCI. The 2017 field testing experience was used to further refine the eight initial groups, with the goal of developing cost performance category criteria. ${ }^{35} 37$ 
Risk-adjusting episode group costs

Episode costs are standardized and risk-adjusted. ${ }^{37}$ The standardization method is used to facilitate comparison and correct for differences related to choices related to a healthcare facility. Different costs related to geographic variations are also eliminated with standardization. Risk adjustment aims to balance factors outside of the clinician's control that can influence spending, for example, variance associated with patient's previous health conditions, illness severity, ages, and comorbidities which are not under a physician's control (eg, in an elective outpatient PCI episode-based cost measure, risk adjustment model would account for a patient's previous history of heart failure). Two different types of risk adjustment are used: standard for all of the episode-based cost measures, the CMS Hierarchical Condition Category Version 22 (CMS-HCC V22) 2016 Risk Adjustment Model; and specific risk adjustors recommended by the Clinical Subcommittees $^{3143}$ during cost measure development. By way of example, the Neuropsychiatric Subcommittee recommended the concurrent diagnosis of aphasia and dysphagia as independent risk variables for intracranial hemorrhage and cerebral infarction.

\section{Aligning episode group costs with quality}

The primary goal of this premise is to avoid low-value care. ${ }^{35}$ The quality metrics to be considered include outcomes of care, processes of care, functional status of patients, and patient experience. The hypothesis is that once cost becomes a well-established metric, it will help guide what is meant by high-value, patient-centered care. This is when the marriage of cost and quality would be ideal: cost metrics would provide accurate, clinically valid, and actionable data to providers, who then would be able to make cost-conscious choices. The TEP and the stakeholder community expressed that the aim is to align episode group costs that have similar characteristics with quality measures and patient outcomes, including nuances of functional status and mortality. As part of measure prioritization and development, analyses were conducted to determine patient cohort overlap with existing quality measures. These analyses were presented to Clinical Subcommittee members to aid in the identification of opportunities for alignment between cost and quality measures, and help guide the choice of which episode groups to develop into cost measures first. CMS is still collecting input on a plane of action into bringing together cost measures with quality. ${ }^{37}$

\section{DISCUSSION}

Neurointerventional (NI) specialists have had significant successes that are by way of example reshaping care delivery for emergent large vessel occlusion patients each day. ${ }^{48}$ Understanding cost is critical to providing value-based healthcare. One of the first obstacles is to better understand how NI specialists fit into these various scenarios. As key providers of essential elements of cerebrovascular treatment, NI specialists will likely have cost of care attributed to them even if the current attribution methodology does not capture this in every instance. Fortunately, there has been significant and explicit NI stakeholder engagement in the development of relevant episode groups. ${ }^{49}$

Cost attribution can be a remarkable challenge when one considers that a physician who is responsible for $30 \%$ of the inpatient evaluation and management services, the other $70 \%$ of the services may be out of their control. The inclusion and exclusion criteria of services to an episode remain subject to initial metrics developed by the CS and TEP. Field-testing allowed for broader feedback from various stakeholders which was then considered by the Clinical Subcommittees. Nonetheless, the political pressure and rapid changes impose a tight timeframe for this complex puzzle. The current Federal administration has given clear signs of revisiting significant parts of the previous administration's plans and visions. ${ }^{50-52}$

Nonetheless, while cost and resource utilization are covered in this manuscript as a specific component of MIPS scoring, it is straightforward to imagine many scenarios where having a better handle on resource utilization could have a meaningful impact on performance metrics of neurointerventionalists. Thus, it is necessary for NI specialists to focus energy on these components as a discipline of practice.

Beyond MIPS and QPP, there are other opportunities for cost to impact on episodes. An example comes from the American Medical Association, which has considered expanding the current procedural terminology (CPT) code sets to include alternative payment models and/or episodes. Neurointerventionalists are familiar with the complex interplay of the CPT system, the Specialty Society RVS Update Committee (RUC), and CMS for determining specific fees for service. How that traditional FFS system might look if expanded to include APMs remains unclear. ${ }^{5354}$ In such a circumstance, cost could be expected to be a vital factor in achieving success.

As a technologically-driven specialty, there is a perception by many of those involved in the NI endeavor that care is expensive. However, NI care is in many situations the standard of care for treatment of cerebrovascular conditions. ${ }^{55-57}$ As a result, emerging data indicate that the number of $\mathrm{NI}$ treatments is rising, and that trend is expected to continue. As NI services become more widespread and thus mainstream, commoditization of the devices used in the clinical space should yield savings opportunities. ${ }^{58}$ The NI literature reflects this and is increasingly recognizing the importance of cost and resource utilization. ${ }^{59-61}$

As systems of care continue to expand, it is likely that NI groups will increasingly co-exist within a single clinically integrated and/or health network. Resource utilization coupled with quality could be used to reward or penalize different members of the system. Decision-making within episodes of care could all come under the rubric of efficient utilization of resources. Examples of these types of decisions exist throughout the NI landscape and include the use of diagnostic arteriography when cheaper non-invasive options are available, use of anesthesia when moderate sedation might be appropriate, or even selecting six vessels selected in a diagnostic study when one might answer the question. Further, as episodes consider both Part A and B costs, operators who might have previously chosen interventional devices based on preference, might recognize a higher value in considering per unit or per treatment cost in the decision-making process. Moreover, as private payers adopt progressive elements of value-based methodology, understanding of costs will inure to the benefit of providers.

\section{CONCLUSION}

Neurointerventional specialists will predominantly participate in the MIPS payment pathway in the present, near, and intermediate term future. Understanding the cost performance category of MIPS is vital to succeeding in this environment. The current round of cost measures included a particular set of trigger episodes of some, but perhaps not crucial, interest to the NI community. It is of paramount importance to gain complete 
facility with the methodology used to proactively offer suggestions for future episodes that will be adjudicated similarly but leaves us with clinical decision room to appropriately serve our patients. Episodic care is simultaneously the method best suited for NI practice and the most likely for our specialty group to succeed.

Acknowledgements We would like to thank Joyce Lam and Sam Bounds for reviewing this work and providing feedback on measure specifications and policy.

Contributors The initial draft was prepared by GS and JH. All authors reviewed the draft, provided meaningful edits, contributed to, and approved, the final version.

Funding The authors have not declared a specific grant for this research from any funding agency in the public, commercial, or not-for-profit sectors.

Competing interests JAH has consulted for Medtronic and Globus in the last 36 months - unrelated. JAH and ABR are supported by Research Grants from the Harvey L. Neiman Health Policy Institute NC and RD and both work for Acumen, LLC. This article does not express the opinions of Acumen, LLC.

Patient consent Not required.

Provenance and peer review Commissioned; internally peer reviewed.

(c) Article author(s) (or their employer(s) unless otherwise stated in the text of the article) 2018. All rights reserved. No commercial use is permitted unless otherwise expressly granted.

\section{REFERENCES}

1 Matveinen P, Knape N. Health expenditure and financing 2013. 2014. http://stats. oecd.org/Index.aspx? DataSetCode=SHA (accessed 7 Jan 2018).

2 Barnett BJC, Berchick ER, Davis KE, et al. Health insurance coverage in the United States : 2016 current population reports. 2017. https://www.census.gov/library/ publications/2017/demo/p60-260.html

3 Manchikanti L, Hirsch JA. Patient Protection and Affordable Care Act of 2010: a primer for neurointerventionalists. J Neurointerv Surg 2012:4:141-6.

4 Manchikanti L, Hirsch JA. The independent payment advisory board: impact on neurointerventionalists. J Neurointerv Surg 2012:4:468-72.

5 Manchikanti L, Helm S, Hirsch JA. The evolution of the patient-centered outcomes research institute. J Neurointerv Surg 2012;4:157-62.

6 Hirsch JA, Barr RM, McGinty G, et al. Affordable care 2014: a tale of two boards. J Neurointerv Surg 2014;6:718-20.

7 Center for Medicare and Medicaid Innovation Established Social Security. https:// www.ssa.gov/OP_Home/ssact/title1 1/1115A.htm (accessed 7 Jan 2018).

8 Centers for Medicare \& Medicaid Services (CMS). About the CMS Innovation Center Center for Medicare \& Medicaid Innovation. 2015 https://innovation.cms.gov/About (accessed 7 Jan 2018).

9 Manchikanti L, Hirsch JA, Barr RM, et al. Physician payment outlook for 2012. J Neurointerv Surg 2012;4:463-7.

10 Hirsch JA, Rosman DA, Liu RW, et al. Sustainable growth rate 2013: time for definitive intervention. J Neurointerv Surg 2013;5:382-6.

11 Rosenkrantz AB, Nicola GN, Allen B, et al. MACRA, MIPS, and the new medicare quality payment program: an update for radiologists. J Am Coll Radiol 2017:14:316-23.

12 Hirsch JA, Harvey HB, Barr RM, et al. Sustainable growth rate repealed, macra revealed: historical context and analysis of recent changes in Medicare physician payment methodologies. AJNR Am J Neuroradiol 2016;37:210-4.

13 Burwell SM. Setting value-based payment goals - HHS efforts to improve US health care. N Eng/ J Med Overseas Ed 2015;372:897-9.

14 Hirsch JA, Leslie-Mazwi TM, Barr RM, et al. The Burwell roadmap. J Neurointerv Surg 2016;8:544-6.

15 114th Congress. United States of America. Medicare Access and CHIP Reauthorization Act of 2015. 2015. https://www.congress.gov/bill/114th-congress/house-bill/2 (accessed 16 Oct 2017).

16 Hirsch JA, Rosenkrantz AB, Ansari SA, et al. MACRA 2.0: are you ready for MIPS? J Neurointerv Surg 2017;9:714-6.

17 Center for Medicare \& Medicaid Services. The quality payment program overview fact sheet. https://qpp.cms.gov/ (accessed 13 Nov 2017).

18 Centers for Medicare and Medicaid Services. Merit-based Incentive Payment System (MIPS) Overview. 2017. https://qpp.cms.gov/mips/overview (accessed 26 Nov 2017).

19 Centers for Medicare \& Medicaid Services (CMS). Strategic objectives for the quality payment program. https://www.cms.gov/Medicare/Quality-Payment-Program/ Resource-Library/Quality-Payment-Program-Key-Objectives.pdf

20 Centers for Medicare \& Medicaid Services (CMS). 2017 quality payment program frequently asked questions, 2017:1-21.

21 Centers for Medicare \& Medicaid Services (CMS). AAPM fact sheet. 2017:1-6 https:// qpp.cms.gov/docs/QPP_Advanced_APMs_in_2017.pdf
22 Quality Payment Program. Alternative Payment Models (APMs) overview. 2016 https://qpp.cms.gov/apms/overview (accessed 13 Nov 2017).

23 Silva E, McGinty GB, Hughes DR, et al. Alternative payment models in radiology: the legislative and regulatory roadmap for reform. J Am Coll Radiol 2016;13:1176-81.

24 Centers for Medicare \& Medicaid Services. Innovation Models | Center for Medicare \& Medicaid Innovation. CMS.gov 2016;0.

25 Rosenkrantz AB, Nicola GN, Allen B, et al. MACRA, alternative payment models, and the physician-focused payment model: implications for radiology. J Am Coll Radiol 2017:14:744-51.

26 Hirsch JA, Leslie-Mazwi TM, Barr RM, et al. The bundled payments for care improvement initiative. J Neurointerv Surg 2016;8:547-8.

27 Hirsch JA, Leslie-Mazwi TM, Nicola GN, et al. PQRS and the MACRA: valuebased payments have moved from concept to reality. AJNR Am J Neuroradiol 2016;37:2195-200.

28 Meehan TM, Harvey HB, Duszak R, et al. Accountable care organizations: what they mean for the country and for neurointerventionalists. J Neurointerv Surg 2016;8:654-7.

29 Centers for Medicare \& Medicaid Services (CMS). Medicare Program; Merit-Based Incentive Payment System (MIPS) and Alternative Payment Model (APM) Incentive Under the Physician Fee Schedule, and Criteria for Physician-Focused Payment Models. Final rule with comment period. 2016

30 Rosenkrantz AB, Goldberg JE, Duszak R, et al. Merit-based incentive payment system participation: radiologists can run but cannot hide. J Am Coll Radiol 2018;15.

31 Centers for Medicare and Medicaid Services. Merit-based Incentive Payment System (MIPS): Episode-Based Cost Measure Field Test Reports Fact Sheet. 2017:1-6.

32 Silva E, McGinty GB, Hughes DR, et al. Traditional payment models in radiology: historical context for ongoing reform. J Am Coll Radiol 2016:13:1171-5.

33 Centers for Medicare \& Medicaid Services (CMS). The quality payment program. https://qpp.cms.gov/ (accessed 12 Jan 2018).

34 Centers for Medicare and Medicaid Services. Proposed rule for quality payment program year 2. 2017 https://www.cms.gov/./Quality.Programs/./Proposed-Rule-forthe-Quality-Payment (accessed 26 Nov 2017).

35 Center for Medicare \& Medicaid Services. QPP year 2 final executive summary. 2017. https://www.cms.gov/Medicare/Quality-Payment-Program/Resource-Library/QPP-Year2-Executive-Summary.pdf.

36 115th Congress (2017-2018). Bipartisan Budget Act of 2018. 2018. https://www. congress.gov/bill/115th-congress/house-bill/1892/text (accessed 15 Feb 2018).

37 Centers for Medicare and Medicaid Services. Episode-based cost measure development for the quality payment program. 2016. https://www.cms.gov/Medicare/ Quality-Initiatives-Patient-Assessment-Instruments/Value-Based-Programs/MACRAMIPS-and-APMs/Episode-Based-Cost-Measure-Development-for-the-Quality-PaymentProgram.pdf

38 Centers for Medicare and Medicaid Services. Value based payment modifier. 2014. http://www.cms.gov/Medicare/Medicare-Fee-for-Service-Payment/PhysicianFeedbac kProgram/ValueBasedPaymentModifier.html (accessed 12 Jan 2018).

39 Rosenkrantz AB, Hirsch JA, Silva E, et al. Radiologists may now be accountable for containing medicare costs and spending under MACRA. J Am Coll Radiol 2017; 14:1298-300.

40 Centers for Medicare \& Medicaid Services (CMS). Merit-Based Incentive Payment System (MIPS): total per capita costs for all attributed beneficiaries measure information form 2017 performance period. 2017. https://www. cms.gov/Medicare/ Quality-Payment-Program/ Resource-Library/2017-CostMeasures.zip

41 Centers for Medicare \& Medicaid Services (CMS). Merit-Based Incentive Payment System (MIPS): medicare spending per beneficiary measure information form 2017 performance period. 2017. https://www.cms.gov/Medicare/Quality-Payment-Program/ Resource-Library/2017-Cost-Measures.zip

42 Centers for Medicare and Medicaid Services. 2015 Measure Information about the Condition Specific Per Capita Costs for All Attributed Beneficiaries Measures, 2017:1-8.

43 Center for Medicare \& Medicaid Services. Risk adjustment overview, 2015

44 Centers for Medicare and Medicaid Services. Announcement of Calendar Year (CY) 2014 Medicare advantage capitation rates and medicare advantage and part D payment policies and final call letter. 2014:1-195 https://www.cms.gov/Medicare/ Health-Plans/MedicareAdvtgSpecRateStats/Downloads/Announcement2014/ (accessed 5 Feb 2018).

45 Acumen LLC/CA: Company Profile - Bloomberg. https://www.bloomberg.com/ profiles/companies/8203100Z:US-acumen-IIc/ca (accessed 12 Jan 2018)

46 Acumen LLC. http://www. acumenllc.com/ (accessed 4 Dec 2017).

47 Rosenkrantz AB, Hirsch JA, Nicola GN. Radiology and the New Medicare/MACRA Patient Relationship Codes. J Am Coll Radiol 2017;14:1180-3.

48 Leslie-Mazwi T, Chandra RV, Baxter BW, et al. ELVO: an operational definition. J Neurointerv Surg 2018:neurintsurg-2018-013792.

49 Hirsch JA, Rosenkrantz AB, Liu RW, et al. The episode, the PTAC, cost, and the neurointerventionalist. J Neurointerv Surg 2017;9:1146-8.

50 Rosenkrantz AB, Nicola GN, Hirsch JA. Anticipated impact of the 2016 federal election on federal health care legislation. J Am Coll Radiol 2017;14:490-3. 
51 Hirsch JA, Rosenkrantz AB, Allen B, et al. AHCA meets BCRA; timeline, context, and future directions. J Neurointerv Surg 2018;10:205-8.

52 Hirsch JA, Rosenkrantz AB, Nicola GN, et al. Contextualizing the first-round failure of the AHCA: down but not out. J Neurointerv Surg 2017;9:595-600.

53 Hirsch JA, Leslie-Mazwi TM, Nicola GN, et al. Current procedural terminology; a primer. J Neurointerv Surg 2015;7:309-12.

54 Hirsch JA, Silva E, Nicola GN, et al. The RUC: a primer for neurointerventionalists. J Neurointerv Surg 2014:6:61-4.

55 Hirsch JA, Yoo AJ, Nogueira RG, et al. Case volumes of intra-arterial and intravenous treatment of ischemic stroke in the USA. J Neurointerv Surg 2009;1:27-31.

56 Rai AT, Seldon AE, Boo S, et al. A population-based incidence of acute large vessel occlusions and thrombectomy eligible patients indicates significant potential for growth of endovascular stroke therapy in the USA. J Neurointerv Surg 2017;9:722-6.
57 Gandhi CD, Al Mufti F, Singh IP, et al. Neuroendovascular management of emergent large vessel occlusion: update on the technical aspects and standards of practice by the Standards and Guidelines Committee of the Society of Neurolnterventiona Surgery. J Neurointerv Surg 2018;10:315-20.

58 Brown P, Cobb M, Smith T, et al. E-045 product cost and utilization in mechanical thrombectomy: a comparison of techniques. J Neurolnter Sur 2016;8:A67.2-8.

59 Chandra RV, Leslie-Mazwi TM, Mehta BP, et al. Does the use of IV TPA in the current era of rapid and predictable recanalization by mechanical embolectomy represent good value? J Neurointerv Surg 2016;8:443-6.

60 Wang C, Ching EC, Hui FK. Aneurysm coil embolization: cost per volumetric filling analysis and strategy for cost reduction. J Neurointerv Surg 2016;8:541-3.

61 Gross BA, Jadhav AP, Jovin TG, et al. Dump the pump: manual aspiration thrombectomy (MAT) with a syringe is technically effective, expeditious, and costefficient. J Neurointerv Surg 2018;10:354-7. 